\title{
BIOINDICADORES VEGETAIS: UMA ALTERNATIVA PARA MONITORAR A POLUIÇÃO ATMOSFÉRICA
}

\author{
Sandra Maria de Figueiredo Aquino \\ Escola Politécnica/UFRJ \\ Josimar Ribeiro de Almeida \\ Escola Politécnica/UFRJ e Instituto de Química/UERJ \\ Roberto Ricardo Rachid Saab Barbosa Cunha ${ }^{4}$
Observatório Urbano/OUERJ/UM-Habitat
}

Gustavo Aveiro Lins

Escola Politécnica/UFRJ

\section{RESUMO}

A poluição atmosférica é responsável por diversos efeitos prejudiciais nos ecossistemas e na saúde humana. As substâncias usualmente consideradas poluentes do ar podem ser classificadas como: compostos de enxofre $\left(\mathrm{SO}_{2}, \mathrm{SO}_{3}, \mathrm{H} 2 \mathrm{~S}\right.$, sulfetos); compostos de nitrogênio ( $\mathrm{NO}, \mathrm{NO}_{2}, \mathrm{NH}_{3}, \mathrm{HNO}_{3}$, nitratos); compostos orgânicos de carbono (hidrocarbonetos, álcoois, aldeídos, cetonas e ácidos orgânicos); monóxido de carbono e dióxido de carbono; compostos halogenados (HCL, HF, cloretos, fluoretos); material particulado (mistura de compostos no estado sólido ou líquido). Usualmente são utilizados sofisticados métodos físico-químicos convencionais para monitoramento, que requerem custos elevados de implantação, operação e manutenção, custos estes, que podem ser minimizados pela adoção de metodologia complementar de biomonitoramento, que é um método experimental que permite avaliar a resposta de organismos vivos à poluição. $\mathrm{O}$ biomonitoramento oferece vantagens como custos reduzidos, eficiência para o monitoramento de áreas amplas e por longos períodos de tempo e, também, avaliação de elementos químicos em baixas concentrações ambientais. As medidas e registros efetuados por redes convencionais de monitoramento da qualidade do ar permitem verificar se normas e limites estabelecidos ou recomendados pela legislação. Entretanto, tais medições não permitem conclusões imediatas sobre as conseqüências de poluentes nos seres vivos. Assim o biomonitoramento deve ser considerado como um método complementar na análise de poluentes. O presente trabalho teve por objetivo identificar por meio de revisão de literatura espécies vegetais dos grupos, angiospermas, briófitas e liquens, utilizadas como bioindicadoras no Brasil, para contribuir com o conhecimento, apresentando informações sobre a utilização de vegetais no biomonitoramento da poluição atmosférica. Os resultados obtidos nesta investigação revelaram a existência de uma grande diversidade de espécies utilizadas em ensaios, destacando-se a Nicotina tabacum, no monitoramento de $\mathrm{O}_{3}$; Tradescantia pallida, de substâncias genotóxicas; Tibouchina pulchra, Gladíolus sp., Citrus sinensis, Spondias dulcis e Panicum maximum, no monitoramento de F; Tillandsia usneoides, no monitoramento de metais pesados e partículas poluentes do ar; Daucus carta $e$ Brassica rapa, no monitoramento de $\mathrm{SO}_{2}$; e Sphagnum sp, de metais, entre eles o cobre e o arsênio.

Palavras-chave: Bioindicador vegetal, Biomonitoramento, Poluição Atmosférica.

\section{ABSTRACT}

The atmospheric pollution is responsable for several prejudicial effects over the ecosystem and the human health. The substances usually considered as air pollutants can be classified as: sulfur compostes $\left(\mathrm{SO}_{2}\right.$, $\mathrm{SO}_{3}, \mathrm{H}_{2} \mathrm{~S}$, sulfetos); nitrogen compostes ( $\mathrm{NO}, \mathrm{NO}_{2}, \mathrm{NH}_{3}, \mathrm{HNO}_{3}$, nitratos); organic carbone compostes (hidrocarbonetos, alcohols, aldeídos, cetonas and organic acids); carbon monoxide and carbon dioxide; halogenado compostes (HCL, HF, cloretos, fluoretos); particle material (compostes of solids or liquids mixtures). Conventional and sophisticated physical-chemical methods are generally used for monitoring, which requires high costs for implantation, operation and maintenance. These 
high costs may be minimized by the utilization of complementary biomonitoring methodology, wich is an experimental method, allowing to evaluate the answer of live organisms to the pollution. The biomonitoring offers advantages such as reduced costs, efficiency for the monitoring of large areas in a long period of time and, also, the evaluation of chemical elements in low environmental concentrations. The measures and registers made by conventional webs of air quality monitoring allows checking norms and limits legally stablished or recommended. However, these measures don't make feasible to take imediatly conclusions about the pollutants consequences on live beings. Therefore, the biomonitoring must be consideres as a complementary method on plllutants analisis. The present study intends to identify, by literature revisioning, vegetables species from the groups angiospermas, briófitas and liquens, utilized such as bioindicators in Brasil, to contribute with the knowledge, introducing informations about the vegetable utilizations in atmospheric pollution biomonitoring. The results obtained over this investigation revealed the existence of a way species diversity, used in essays, standing out the Nicotine tabacum, on $\mathrm{O}_{3}$ monitoring; Tradescantia pallida, of genotoxicas substances; Tibouchina pulchra, Gladíolus sp., Citrus sinensis, Spondias dulcis e Panicum maximum, on $\mathrm{F}$ monitoring; Tillandsia usneoides, on heavy metal and particle air pollutants monitoring; Daucus carta e Brassica rapa, on $\mathrm{SO}_{2}$ monitoring; and Sphagnum sp, of metals as copper and arsenium.

Key-words: Vegetable Bioindicators, Biomonitoring, Atmospheric Pollution.

\section{INTRODUÇÃO}

A poluição atmosférica é responsável por diversos efeitos prejudiciais nos ecossistemas e na saúde humana. As substâncias usualmente consideradas poluentes do ar podem ser classificadas como: compostos de enxofre $\left(\mathrm{SO}_{2}, \mathrm{SO}_{3}, \mathrm{H}_{2} \mathrm{~S}\right.$, sulfetos); compostos de nitrogênio ( $\mathrm{NO}, \mathrm{NO}_{2}, \mathrm{NH}_{3}, \mathrm{HNO}_{3}$, nitratos); compostos orgânicos de carbono (hidrocarbonetos, álcoois, aldeídos, cetonas e ácidos orgânicos); monóxido de carbono e dióxido de carbono; compostos halogenados (HCL, HF, cloretos, fluoretos); material particulado (mistura de compostos no estado sólido ou líquido) (DERISIO 2000). O monitoramento é uma das formas de se verificar a qualidade do ar de uma determinada região, mas avaliar o comportamento do poluente no meio ambiente, ou seja, monitorar sua ação em organismos vivos, apesar de toda tecnologia existente, não tem sido fácil.

Os conhecimentos dos efeitos da poluição do ar na vegetação e o uso de bioindicadores, utilizando plantas para monitorar a qualidade do ar, ainda são limitados em países em desenvolvimento, e na Região Norte, são raros os trabalhos com relação ao assunto.

O presente trabalho tem por objetivo identificar por meio de revisão de literatura espécies vegetais dos grupos, angiospermas, briófitas e liquens, utilizadas como bioindicadoras no Brasil, para contribuir com o conhecimento, apresentando informações sobre a utilização desses vegetais no biomonitoramento da poluição atmosférica.

Na maioria das vezes a avaliação da presença de poluentes no ambiente é feita através de metodologias que empregam recursos químicos, físicos ou físico-químicos, através do uso de aparelhos, em muitos casos bastante sofisticados e caros. Avaliar o comportamento do poluente no ambiente, ou seja, monitorar a sua ação através de organismos vivos é um tópico relativamente novo nas ciências ambientais, que tem sido chamado de biomonitoramento ou bioindicação LIMA (2001, p. 95-115). 
O biomonitoramento atmosférico usa vegetal como ferramenta na avaliação da qualidade do ar, recorre a metodologias simples e reproduz de modo mais fiel, a qualidade do ar, uma vez que avalia respostas de sistemas biológicos de modo integrado, ou seja, a ação de vários poluentes ao mesmo tempo e em condições atmosféricas reais. É de reconhecimento mundial a utilização do biomonitoramento como ferramenta na avaliação da qualidade ambiental (LIMA et al.2005).

\section{MATERIAIS E MÉTODOS}

O presente trabalho trata de um levantamento bibliográfico baseado em revisão sistemática da literatura, (coleta de dados), visando reunir conhecimentos divulgados com relação ao uso de bioindicadores vegetais, como método complementar de monitoramento da poluição atmosférica.

Não se levou em consideração o período da publicação, foram aceitos todos os trabalhos disponíveis, considerando-se sua escassez na área em estudo.

Antes de proceder à pesquisa bibliográfica, foi definida a seleção de palavraschave: bioindicador vegetal, biomonitoramento e poluição atmosférica.

\section{RESULTADOS E DISCUSSÕES}

Os resultados encontrados com a pesquisa bibliográfica quanto ao uso de bioindicadores vegetais em biomonitoramento de poluição atmosférica, foram separados em três grupos: angiospermas, briófitas e liquens.

Foram listadas 19 espécies utilizadas como bioindicadores vegetais de poluição atmosférica, sendo 18 espécies pertencentes ao grupo das angiospermas, e 01 das briófitas. Dos liquens não foram identificadas as espécies.

A seguir encontram-se descrições sucintas dos bioindicadores mais frequentemente utilizados, no Brasil, conforme levantamento efetuado na presente revisão sistemática.

\section{Angiospermas}

É o maior grupo de acordo com a evolução dos vegetais e também o que tem maior número de espécies utilizadas como bioindicadoras da poluição atmosférica.

Tradescantia

O Gênero Tradescantia, pertencente à Família Commeliaceae, é bastante utilizado como bioindicador através da espécie Tradescantia pallida cv. Púrpura, e dos clones 4430, KU 20, BNL 4430. 
Em 1998, o professor Paulo Saldiva, descobriu as propriedades da Tradescantia pallida cv. púrpura vulgarmente conhecida como coração-roxo, na Universidade de Chicago, nos Estados Unidos, por meio de um pesquisador chinês. "Essa planta é fácil de cultivar em qualquer lugar e tem alta resistência, seu DNA (ácido desoxirribonucléico) registra os poluentes e suas mudanças". (Portal do governo do Rio Grande do Sul)

O clone híbrido 4430 de Tradescantia vem sendo utilizado em bioensaios (TradMCN, Trad-SH) que avaliam o efeito genotóxico de várias substâncias. Este estudo objetivou estabelecer o padrão estrutural da folha do clone e verificar se existem características anatômicas afetadas pela poluição, que podem ser utilizadas como bioindicadoras. Os resultados mostraram que a Tradescantia clone 4430 expostas em São Paulo, sofreu os efeitos da poluição aérea, uma vez que houve uma redução nas dimensões dos estômatos, no metaxilema e na espessura da folha. Cabe destacar que os resultados aqui obtidos, podem ser uma indicação indireta do efeito da poluição no crescimento da planta e reforçam a idéia que a poluição afeta o balanço hídrico e, consequentemente, a taxa de fotossíntese conforme já registrado para outras espécies, de acordo com ALVES et al. (2001, p. 567-576).

O bioensaio Trad-MCN, que se baseia na contagem de micronúcleos em célulasmãe de grãos de pólen na Tradescantia e permite determinar a capacidade de substâncias causarem danos ao material genético, levando à formação de micronúcleos ao fim da divisão celular. Uma freqüência elevada de micronúcleos nas análises é o indicador de que as substâncias afetam a planta. A estrutura do DNA e seus mecanismos de replicação e reparo são universais para todos os seres vivos, ou seja, o que causa danos ao material genético dos vegetais pode vir a causar danos aos cromossomos de seres humanos. Esse teste foi desenvolvido em 1978, segundo LIMA, (2001).

SANTANNA (2003,150p.) validou o uso de Tradescantia pallida Purpúrea, empregando o bioensaio Trad-MCN (mutações em células-mãe de pólen), para monitoramento do potencial mutagênico de poluentes urbanos. Verificou também, o potencial do bioensaio Trad-SH (mutações em pelos estaminais) com inflorescências do clone KU-20 para avaliação de riscos em curto prazo.

FERREIRA (2004, 99p.), submeteu as plantas do gênero Tradescantia, sendo o clone BNL 4430, mundialmente conhecido e utilizado para monitorar poluições da água, ar e solo; e o clone KU 20 por ser altamente mutável em baixas temperaturas é menos utilizado, sendo reservado para o estudo da natureza genética das mutações. Foi utilizado o teste de mutação em pêlos estaminais da Tradescantia, ou simplesmente o Trad-SHM. Foi avaliado o potencial genotóxico da poluição do ar ambiente no Parque do Ibirapuera, e 
ainda testar o clone KU 20 para exposição in situ. Foram colhidas 40 inflorescências de cada clone, de setembro de 2002 a agosto de 2003. Os resultados foram comparados com os dados da poluição do ar no período, fornecidos pela CETESB. As análises indicaram que as variações nos eventos de mutação ao longo do ano, em KU 20 estiveram relacionadas significativamente e positivamente com as variações nas concentrações de $\mathrm{CO}, \mathrm{MP}_{10}, \mathrm{NO}_{2}$ e $\mathrm{SO}_{2}$ e negativamente com as variações na intensidade de radiação e na temperatura do ar. Para o clone BNL 4430 houve correlação com o $\mathrm{SO}_{2}, \mathrm{NO}_{2}, \mathrm{CO}$ e $\mathrm{MP}_{10}$. Os fatores climáticos não tiveram relação significativa com os eventos mutagênicos neste clone. Portanto, para nosso clima os dois clones podem ser utilizados como bioindicadores.

A espécie Tradescantia pallida cv. purpura foi escolhida para o biomonitoramento no município de Santo André, sendo um dos pontos escolhidos a escola SESI 221. Com o objetivo de mostrar que a metodologia é excelente para educação ambiental, envolvendo alunos e professores. Plantas da bioindicadora foram expostas nos locais de estudo para posterior análise laboratorial das mutações ocorridas no material genético (DNA) das células de grãos de pólen. Os resultados mostraram que a formação de micronúcleos foi muito maior na área de maior intensidade de poluição atmosférica, LUIZ (2005, p.17).

O primeiro Programa de Biomonitoramento da Qualidade do $\mathrm{Ar}$ da Cidade do Salvador-Ba, utilizando vegetais definiu oito estações experimentais no perímetro urbano, onde foram expostos vasos, biomonitores ativos, bem como avaliadas plantas locais, biomonitores passivos. O surgimento de micronúcleos nas células da Tradescantia $\mathrm{sp}$, foi uma indicação da presença de substâncias carcinogênicas (LIMA, 2005, 10p).

Segundo CARVALHO (2005, p.459-462), estudos mostram que parece razoável considerar que a Tradescantia apresenta uma radiossensibilidade comparável à das células de mamíferos. Isso contribui para o crescimento do interesse na utilização da planta para detecção de agentes ambientais com potencial mutagênico. Concluiu o autor que, com relação às radiações ionizantes, a Tradescantia pallida, poderá ser utilizada como padrão para estudos futuros de mutagenicidade e aberrações cromossômicas, por meio da comparação com efeitos produzidos por outros tipos de radiação, avaliação do efeito da associação da radiação com drogas ou outros agentes químicos, além da biomonitoração de ambientes de alto risco.

\section{Tillandsia usneoides}

Conhecida popularmente como barba-de-bode é muito utilizada em arranjos florais, além disso, as bromélias têm sido utilizadas de forma sistemática, para detectar a 
presença de metais pesados no ar na grande São Paulo, com o objetivo de traçar um mapa das fontes de poluição por metais e compará-las com perfil de industrialização e urbanização da região monitorada, está sendo realizado um monitoramento contínuo (SAIKI, 2004).

Ainda segundo Saiki, estudos com bromélias, chamadas bioindicadoras vegetais, para avaliar o impacto da poluição ambiental começaram a ser realizados nas primeiras décadas do século passado, e que vária s pesquisas foram feitas na Europa. E que, nos últimos anos, também desenvolvem projetos a respeito do tema Argentina, Chile, México e Jamaica.

Recentemente, três quilos de exemplares de T. usneoides foram instalados as véspera do carnaval em Salvador, para monitorar a presença e a proporção de metais pesados e partículas poluentes no ar, durante os cinco dias de festa. A Tillandsia é capaz de reter em sua superfície escamosa partículas microscópicas de metais pesados e poluentes, capazes de afetar a saúde humana (SEMARH, 2007).

\section{Nicotiana tabacum}

Vulgarmente conhecida como tabaco, pertence à família Solanaceae. A espécie Nicotiana tabacum foi utilizada como biomonitor ativo, no primeiro Programa de Biomonitoramento da Qualidade do $\mathrm{Ar}$ da Cidade do Salvador-Ba, onde também foram utilizados biomonitores passivos. Dentre as atividades já realizadas, estão a implantação do experimento nos pontos amostrais, palestras em escolas e análises laboratoriais. Já foram realizadas seis coletas, de um modo geral, as respostas dos biomonitores se diferem significativamente nos pontos onde o número de veículos que circulam nestes pontos quando comparados com os demais em estudo é significativamente maior, o que justifica o comportamento diferenciado dos vegetais, LIMA (2005, 10p.).

PEDROSO (2006, 60p.) utilizou a cultivar Nicotiana tabacum "Bel W3" como bioindicadora do ozônio na cidade de São Paulo. As plantas foram expostas em pontos que são monitorados por estações medidoras da CETESB e são locais onde as concentrações de ozônio atingem valores elevados. Folhas com e sem necrose foram coletadas para processamento segundo técnicas usuais empregadas em anatomia vegetal. Os resultados obtidos indicaram que a folha de tabaco Bel W3 sofre alterações em sua estrutura, mesmo naquela que não apresenta necrose, quando a planta é submetida aos poluentes aéreos urbanos. 
A variedade Bel W3 vem sendo utilizada há décadas na Europa e Estados Unidos como um bioindicador específico de poluentes foto-oxidantes, principalmente o ozônio troposférico, CETESB (2007).

O tabaco também foi testado em dez cidades da Europa, no projeto EuroBionet, durante os meses de agosto e setembro de 2000, em que os primeiros resultados demonstraram um gradiente de impacto de ozônio ( KLUMPP, 2001).

\section{Tibouchina pulchra}

Conhecida como manacá-da-serra, pertence à família Melastomataceae. MORAES et al. (2000, p. 443-449 ) verificaram redução em altura, diâmetro do caule e biomassa de folhas, ramos, raízes e razão raiz/parte aérea em Tibouchina pulchra Cogn. exposta em condições padronizadas, em três regiões de Cubatão/SP. Apesar de não apresentarem danos visíveis, foram submetidos a condições ambientais estressantes, portanto os níveis de poluição aérea ainda são fitotóxicos por $\mathrm{PAN} \mathrm{e}_{3}$.

\section{Mangifera indica}

Pertence à Família anacardiaceae, a mangueira é amplamente utilizada como biomonitor na Índia. Está sendo utilizada em biomonitoramento em Salvador/BA, onde foram avaliadas respostas fisiológicas, a exemplo da concentração de enxofre foliar e alterações na anatomia foliar.

Atualmente, o Programa de Biomonitoramento do $\mathrm{Ar}$ na região do Pólo Petroquímico de Camaçari-Ba (PPC), vem utilizando a mangueira no biomonitoramento passivo das emissões do PPC (LIMA, 2001, p.95-115).

\section{Byrsonimia crassifólia [L] Rich}

PAULA et al. (2005, p.137-148) avaliaram os efeitos causados pelo flúor sobre parâmetros químicos e bioquímicos de folhas jovens e maduras de plantas de Byrsonima crassifólia $\{L\}$ Rich, pertencente à Família Malpiguiaceaenos, conhecida como muruci, nos arredores da fábrica de alumínio da ALBRAS, no município de Barcarena/PA. Quanto aos teores de carboidratos e proteínas solúveis totais e clorofila a, a região da fábrica, a 200 $\mathrm{m}$ da fonte de liberação de flúor gasoso, apresentou resultados inferiores, aos na região de Água Verde, a 4 km da fábrica. Assim como folhas de plantas localizadas próximas à fábrica, apresentaram sintomas de toxidez ao flúor, como clorose e lesões necróticas, os quais não foram observados na região de Água Verde. 


\section{Citrus sinensis}

FAHL (2003, 100p) avaliou a emissão de flúor do pólo cerâmico de Santa Gertrudes/SP e sua dispersão geográfica, através da determinação dos teores de flúor acumulados em folhas de plantas de espécies vegetais de valor econômico. A dicotiledônea Citrus sinensis, da Família Rutáceae, acumulou os maiores teores foliares de flúor.

\section{Genipa americana}

SILVA et al. (2000, p.385-393) utilizaram plântulas e mudas de diversas espécies arbóreas nativas no Parque Estadual do Rio Doce, em Minas Gerais, para avaliar o efeito do $\mathrm{F}$ presente em chuva simulada, em ensaios de biomonitoramento ativo. A espécie Genipa americana, da Família Rubiaceae, conhecida como genipapo, mostrou-se mais resistente à ação do poluente, apresentando os menores índices de injúrias foliares, bem como a menor taxa de acúmulo diário de $\mathrm{F}$.

\section{Coffea arábica}

Também foi testada por FAHL (2003, 100p) em avaliação de emissão de flúor do pólo cerâmico de Santa Gertrudes/SP e sua dispersão geográfica, através da determinação dos teores de flúor acumulados em folhas de plantas de espécies vegetais de valor econômico, plantas de C. arábica, da Família Rubiaceae, mostraram maior tolerância ao flúor atmosférico.

\section{Saccharum oficinarum}

Segundo ARNDT, et al. (1995), alterações no metabolismo causadas pelo flúor podem conduzir a sintomas visíveis externamente, seja por ação de altas concentrações de curta duração ou efeitos crônicos por imissões continuadas. Em plantas de folhas de cana-de- açúcar, assim como em outras gramíneas (monocotiledôneas), que o primeiro sintoma é geralmente clorose na ponta da folha e nas margens de folhas em desenvolvimento, e ainda que a clorose se estende às áreas intercostais que finalmente se tornam necrosadas.

FAHL (2003, 100p) avaliou emissão de flúor do pólo cerâmico de Santa Gertrudes/SP e sua dispersão geográfica, através da determinação dos teores de flúor acumulados em folhas de plantas de espécies vegetais de valor econômico, e verificou que plantas de cana-de-açúcar acumularam menores valores de flúor que outras gramíneas. 


\section{Spondias dulcis}

Registrou-se o uso da espécie por SILVA et al. (2000, p.385-393), em biomonitoramento ativo de chuva simulada contendo flúor, mostrando-se uma das espécies mais sensíveis, do grupo estudado pelos pesquisadores, à ação do poluente. Por isso, foi considerada por eles a espécie como um potencial bioindicador da presença de $\mathrm{F}$ em ambientes sujeitos as emissões atmosféricas contendo gás fluorídico e outros fluoretos gasosos.

\section{Panicum maximum}

Plantas de $P$. maximum Jacq. também foram submetidas a chuvas simuladas com soluções de fluoreto de potássio, com o objetivo de identificar as injúrias causadas pelo flúor, como poluente atmosférico. $O$ experimento confirma a maior sensibilidade de $P$. maximum ao flúor (CHAVES ET AL. 2002, 395-406).

Também foi testada por FAHL (2003, 100p) em avaliação de emissão de flúor do pólo cerâmico de Santa Gertrudes/SP e sua dispersão geográfica, através da determinação dos teores de flúor acumulados em folhas de plantas de espécies vegetais de valor econômico, plantas de capim colonião crescidas próximas do centro emissor, apresentaram alta sensibilidade ao flúor presente na atmosfera, mostrando folhas com clorose distribuídas por todas as regiões da lâmina foliar e necrose. Verificou-se ainda, através de análise estrutural de cortes de folhas, sensível redução do número de cloroplastos nas células do mesófilo. Essas alterações associadas a outros possíveis danos a nível interno da planta, certamente acarretam considerável redução de sua capacidade produtiva.

Ainda com relação à chuva simulada de flúor, OLIVA; FIGUEIREDO (2005, p.389397), avaliaram o potencial indicativo da presença de fluoreto em várias espécies de gramíneas forrageiras de ampla distribuição geográfica na região tropical, entre elas a Panicum maximum Jacq. cv. Todas as plantas mostraram padrões de acúmulo diferenciados, as plantas de $P$. maximum cv., Colonião se adaptaram muito bem as técnicas do cultivo padronizado, com velocidade de resposta a necrose e clorose, por isso foi caracterizada como bioindicadora de resposta.

\section{Chloris gayana}

Plantas de Chloris gayana também foram submetidas a chuvas simuladas com soluções de fluoreto de potássio, com o objetivo de identificar as injúrias causadas pelo 
flúor, como poluente atmosférico. Em $C$ gayana, não foram observadas alterações nos cloroplastos e outros sintomas foram bem discretos (CHAVES ET AL. 2002, 395-406).

Com relação à chuva simulada de flúor, OLIVA; FIGUEIREDO (2005, p.389-397), avaliaram o potencial indicativo da presença de fluoreto em várias espécies de gramíneas forrageiras de ampla distribuição geográfica na região tropical, entre elas a C. gayana que se apresentou como espécie tolerante.

\section{Lolium multiflorum}

Usando Lolium multiflorium Lam como bioindicador para verificar a influência da poluição atmosférica proveniente de uma fábrica de alumínio, instalada em Ouro Preto/MG, (PRADO, 1993, p.58-64), verificou que as plantas cultivadas em pontos mais próximos a fonte poluidora apresentaram maior concentração de fluoretos.

Com relação à chuva simulada de flúor, (OLIVA; FIGUEIREDO, 2005, p.389-397), avaliaram o potencial indicativo da presença de fluoreto em várias espécies de gramíneas forrageiras de ampla distribuição geográfica na região tropical, entre elas a Lolium multiflorum ssp, que foi caracterizada como espécie tolerante.

\section{Gladiolus sp}

PRADO (1993, p.58-64), usando Gladiolus sp como bioindicadores para verificar a influência da poluição atmosférica proveniente de uma fábrica de alumínio, instalada em Ouro Preto/MG, verificou que as plantas cultivadas em pontos mais próximos a fonte poluidora apresentaram maiores valores médios de área foliar necrosada.

ARNDT et al. (1995), verificou ocorrência de necrose nas pontas das folhas, mas sem sintomas intermediários de clorose. Entre as áreas necrosadas e as verdes da folha ocorre geralmente uma estreita zona de transição clorótica.

Cultivares brasileiras de Gladiolus foram expostas a local altamente poluído por fluoretos, nas proximidades do complexo industrial de Cubatão/SP. A intensidade e distribuição das lesões na lâmina foliar variaram entre as cultivares. Ocorreu acúmulo de flúor nas folhas, redução de peso seco das folhas e flores, além de necroses nas pontas e margens das folhas. As cultivares white Friendship e Eurovision foram sugeridas para uso como bioindicadoras da poluição por fluoretos ( KLUMPP et al., 1997).

\section{Phaseolus vulgaris}

O feijão carioquinha como é conhecido vulgarmente a espécie Phaseolus vulgaris, vem sendo pesquisado na Bahia, no biomonitoramento do Pólo de Camaçari e em 
Salvador. Respostas fisiológicas e bioquímicas de Phaseolus vulgaris foram empregadas na avaliação dos efeitos das emissões do PPC na vegetação. (LIMA, 2001; LIMA, 2005).

\section{Daucus carota}

ALMEIDA, AGUIAR (2002, p.171-180) utilizaram plantas de Daucus carota (cenoura) como bioindicadoras, comprovadamente sensíveis ao dióxido de enxofre $\left(\mathrm{SO}_{2}\right)$, para verificar o grau de poluição atmosférica, nas redondezas de uma indústria têxtil, na cidade de Petrópolis/RJ. A influência da poluição sobre as plantas foi baseada na redução dos pesos frescos e secos das plantas, crescendo em cada uma das cinco estações de amostragem. As plantas cultivadas a cinqüenta e noventa metros de distância da fonte poluidora, apresentaram menor crescimento e, conseqüentemente, redução dos pesos frescos e secos. O crescimento das plantas medido pelo peso fresco, mostrou-se diferente entre os pontos próximos à indústria e à estação de controle a dez quilômetros. Drásticas reduções no peso fresco foram observadas próximas à fonte poluidora. Cerca de $90 \%$ de decréscimo no peso fresco foi observado entre as plantas cultivadas nas proximidades da indústria, em relação ao controle.

Utilizando plantas de Daucus carota, para verificar a influência da contaminação atmosférica causada por uma indústria têxtil, em Teresópolis/RJ, (MENDONÇA, SILVA e SILVA, 1991, p. 37-40) constatou a redução do crescimento nas plantas em diferentes distâncias e altitudes, bem como, redução no peso seco e fresco, além de necroses e cloroses nas folhas de cenoura.

\section{Brassica rapa}

Também foi utilizada por (ALMEIDA; AGUIAR, 2002, p.171-180) como plantas bioindicadoras, comprovadamente sensíveis ao dióxido de enxofre $\left(\mathrm{SO}_{2}\right)$, para verificar o grau de poluição atmosférica, nas redondezas de uma indústria têxtil, na cidade de Petrópolis/RJ. Assim como em plantas de cenoura, as de B. rapa (nabo) sofreram influência da poluição que teve como consequencia a drástica redução no peso fresco. Utilizando plantas de Daucus carota e Brassica rapa, para verificar a influência da contaminação atmosférica causada por uma indústria têxtil, em Teresópolis/RJ, (MENDONÇA, SILVA e SILVA, 1991, p. 37-40) constatou a redução do crescimento nas plantas em diferentes distâncias e altitudes, bem como, redução no peso seco e fresco, além de necroses e cloroses nas folhas de nabo.

\section{Caesalpinia echinata}


Plantas jovens de Caesalpinia echinata Lam. foram expostas em três regiões da cidade de São Paulo com características de contaminação do ar, em áreas próximas a estações de monitoramento da qualidade do ar da CETESB. Após quinze meses foi verificado que as plantas apresentaram redução no crescimento em altura, aumento do número de ramos, e redução da biomassa de folhas, caules, raízes e planta inteira CUNHA (2006, 62p.).

\section{Briófitas}

São plantas simples, avasculares, na maioria terrestre, de lugares úmidos e de pequeno porte (alguns centímetros). Fixam-se no solo por pequenos filamentos, os rizóides, que também fazem à absorção de água e sais. Dentre as espécies da Divisão Bryophyta estão os musgos (SILVA, 2003).

\section{Sphagnum}

No final de 1995, foi iniciado um Programa de Biomonitoramento do Ar na região do Pólo Petroquímico de Camaçari-Ba (PPC), com hortaliças, o musgo Sphagnum sp, foi utilizado para "validar" os resultados. Os dados obtidos com os biomonitores foram compatíveis com os dados provenientes das análises físico-químicas, sendo que os vegetais, especialmente o Sphagnum $\mathrm{sp}$, acumularam concentrações consideravelmente mais elevadas do que as medições físico-químicas. Entre os metais foram analisados o cobre e o arsênio, que mostraram concentrações mais elevadas nas estações mais próximas de uma indústria benefici adora de cobre (LIMA, 2001 p.95-115).

Programa de Biomonitoramento da Qualidade do Ar em Salvador-Ba, utilizando vegetais também utilizou o Shagnum sp, reconhecido internacionalmente por acumular metais pesados. As atividades já realizadas foram a implantação de experimento nos pontos amostrais, palestras em escolas e análises laboratoriais. Já foram realizadas seis coletas, de um modo geral, as respostas dos biomonitores diferem significativamente nos pontos onde o número de veículos que circulam nestes pontos quando comparados com os demais em estudo é significativamente maior, o que justifica o comportamento diferenciado dos vegetais, LIMA (2005, 10p).

\section{Líquens}

Liquens são organismos resultantes da associação do tipo mutualismo entre fungos e algas unicelulares, tradicionalmente, uma simbiose. $O$ fungo, geralmente um ascomiceto, é o chamado micobionte, heterótrofo, que predomina na associação. 0 
organismo fotossintetizante, unicelular, chamado ficobionte, é uma alga verde ou uma cianobactéria. A associação é tão íntima e equilibrada que durante muito tempo os liquens foram considerados vegetais, pois parecia um único tipo de organismo (JÚNIOR, SASSON, 2003).

No Brasil há 2.800 espécies de liquens já listadas, mas não existem dados para o mapeamento da distribuição de elementos indicando os níveis de poluição, segundo SAIKI (2004).

Os liquens são sensíveis a diversos poluentes e têm sido utilizados de várias maneiras no monitoramento passivo, tanto como indicadores de reação como de acumulação (ARNDT, 1995).

\section{CONCLUSÃO}

Os resultados obtidos nesta investigação sobre o uso de bioindicadores vegetais em processos de poluição atmosférica revelaram a existência de uma grande diversidade de espécies utilizadas em ensaios de biomonitoramento.

Desse modo, concluímos que muitos bioindicadores vegetais encontram-se associados a um determinado poluente atmosférico destacando-se:

- Nicotina tabacum, (tabaco), no monitoramento de $\mathrm{O}_{3}$;

- Tradescantia pallida cv. Purpúrea (coração-roxo), monitoramento de substâncias genotóxicas presentes em material particulado da atmosfera urbana;

- Tibouchina pulchra (manacá-da-serra), Gladíolus sp., Citrus sinensis, Spondias dulcis, Panicum maximum (colonião), no monitoramento de F;

- Tillandsia usneoides (barba-de-bode), no monitoramento de metais pesados e partículas poluentes do ar;

- Daucus carta e Brassica rapa, no monitoramento de $\mathrm{SO}_{2}$;

- Sphagnum sp, de metais, entre eles o cobre e o arsênio.

Finalmente, espera-se uma divulgação maior dos bioindicadores vegetais já reconhecidos no biomonitoramento para o controle da qualidade ambiental.

\section{REFERÊNCIAS}

ALMEIDA, J. R.; AGUIAR, L. A. Efeito da poluição por dióxido de enxofre $\left(\mathrm{SO}_{2}\right)$ sobre bioindicadores hortícolas. Ciências Ambientais. (ALMEIDA, J. R.). Rio de Janeiro. Thex Editora. 2002, p.171-180. 
ALMEIDA, V. S. Alterações nos teores de enxofre e de metabólitos indicadores de estresse em árvores adultas de mangifera indica L. CV. espada expostas à poluição aérea e edáfica, na região do pólo petroquímico de camaçari/BA. Salvador. 2000. Monografia (Pós-graduação em geoquímica e meio ambiente) - Universidade Federal da Bahia.

ALVES, E. S.; GIUSTI, P. M.; DOMINGOS, M.; SALDIVA, P. H. N.; GUIMARÃES, E. T. e LOBO, D. J. A. Estudo anatômico foliar do clone híbrido 4430 de Tradescantia: alterações decorrentes da poluição aérea urbana. Rev. Bras. Bot., São Paulo, v. 24, n. 4, p. 567-576, dez.2001. Disponível em: http://www.scielo.br /. Acesso em: 23/02/2007.

ARNDT, U.; FLORES, F.; WEINSTEIN, L. Efeitos do flúor sobre as plantas. 1. ed. Porto Alegre: Ed. da Universidade, 1995. 155p.

BRASIL. Lei $n^{\circ}$ 6.983, de 31/08/1981. Dispõe sobre a Política Nacional do Meio ambiente, seus fins e mecanismos de formulação e aplicação e dá outras providências. Diário Oficial da União de 02/09/1981. Disponível em : http://www.mma.gov.br/ . Acesso em: 23/02/2007.

CARVALHO, B. A. Ecologia e Poluição. ed. única. Rio de Janeiro: Livraria Freitas Bastos S. A., 1975.

CARVALHO, H.A. A Tradescantia como bioindicador vegetal na monitoração dos efeitos clastogênicos das radiações ionizantes. Radiol Bras v.38 n.6, São Paulo, 2005, P.459-462.Disponível em:http:// www.scielo.br/cgi-bin/wxis.exe/iah/. Acesso em: 03/03/2007.

CHAVES, A. C. F.; SILVA, E. A. M.; AZEVEDO, A. A.; CANO, M. A. O. \& MATSUOKA. K. Ação do flúor dissolvido em chuva simulada sobre a estrutura foliar de Panicum maximum Jacq. (colonião) e Chloris gayana Kunth. (capim-rhodes) - Poaceae. Acta. Bot. Brás. 16(4): 2002. p. 395-406.

CETESB. 2006. Relatório anual da qualidade do ar no Estado de São Paulo - 2005. Disponível em: http://www.cetesb.sp.gov.br. Acesso em: 01/03/2007.

CONAMA. Resoluções do Conama: resoluções vigentes publicadas entre julho de 1984 e maio de 2006 - 1. ed. - Brasília: Conselho Nacional do Meio Ambiente, 2006.808p.

CONAMA. Resolução no 382, de 26 de dezembro de 2006. Ministério do Meio Ambiente. Disponível em: http://www.mma.gov.br/port/conama/res/res90/. Acesso em: 12/02/2007. CUNHA, A.L. Avaliação do crescimento de plantas jovens de Caesalpinia echinata Lam. (pau-brasil) expostas à poluição aérea em diferentes regiões da cidade de São 
Paulo, SP. Dissertação (Mestrado em Biodiversidade vegetal e Meio Ambiente) - Instituto de Botânica da Secretaria do Meio Ambiente. São Paulo.2006, 62p.

Declaração de Estocolmo sobre o Meio Ambiente Humano. Disponível em: www.dhnet.org.br/direitos/sip/onu/doc. Acesso em: 02/04/2007.

DERISIO, J.C. Introdução ao controle de poluição ambiental. 2. ed., São Paulo: Signus, 2000 p. 87-128.

Efeitos da poluição: Bioindicadores. Portal do Governo do Estado. CETESB. São Paulo, 28 março 2007. Disponível em: www.cetesb.sp.gov.br. Acesso em: 28/03/2007 FAHL, I.A.F. Caracterização geográfica da dispersão do flúor, através de teores foliares, em espécies vegetais de interesse econômico, a partir do pólo cerâmico de Santa Gertrudes-SP. Dissertação (Mestrado em Geografia) - Instituto de Geociências e Ciências Exatas, Universidade Estadual Paulista, Rio Claro, 2003, 100p.

FERREIRA, M.I. Avaliação do potencial genotóxico da poluição atmosférica no Parque do Ibirapuera, São Paulo, com o bioensaio TRAD-SHM da Tradescantia / Evaluation of genotoxic of air pollution at lbirapuera Park, São Paulo. Tese (para obtenção do grau de Mestre) - Universidade de São Paulo. Faculdade de Saúde Pública, São Paulo, 2004.99p.

GOUVEIA, N. ET AL. Hospitalizações por causas respiratórias e cardiovasculares associadas à contaminação atmosférica no Município de São Paulo, Brasil / Respiratory and cardiovascular hospitalizations associated with air pollution in the city of São Paulo, Brazil. Cad. Saúde pública = Rep. Public health;22(12): 2669-2677, 2006. Disponível em: http://bases.bireme.br/cgi-bin/wxislind.exe/iah/online/. Acesso em: 03/04/2007.

JOLY, A.B. Botânica: Introdução à taxonomia vegetal. 13. ed. São Paulo: Cia. Editora Nacional. 2002, 777p.

JÚNIOR, C.S.; SASSON, S. Biologia. v. único. 3. ed. reform. São Paulo: Saraiva, 2003. $640 p$

KLUMPP, A. Utilização de bioindicadores de poluição em condições temperadas e tropicais. In: Maia, N. B. Martos, H. L. \& Barrella, W.: Indicadores ambientais: conceitos e aplicações. São Paulo:EDUC, 2001. p.77 - 94.

KLUMPP, A.; ANSEL, W.; KLUMPP, G.; FOMIN, A. Um novo conceito de monitoramento e comunicação ambiental: a rede européia para a avaliação da qualidade do ar usando plantas bioindicadoras (EuroBionet). Rev. Bras. Bot., v. $24 \mathrm{n}$. 4. supl., 2001, p. 511-518. 
KLUMPP, A.; MODESTO, I.F.; MARISA, D.; KLUMPP, G. Sensibilidade de cultivares de Gladiolus à poluição por fluoretos, e sua aptidão para a bioindicação. Revista $P A B$ Pesquisa agropecuária Brasileira. v.32, n. 3. 1997. Disponível em: http://atlas.sct.embrapa.br/pab/pab.nsf/. Acesso em: 28/03/2007.

LIMA, J. S. Processos biológicos e o biomonitoramento: aspectos bioquímicos e morfológicos. In: Maia, N. B. Martos, H. L. \& Barrella, W. Indicadores ambientais: conceitos e aplicações. São Paulo: EDUC, 2001. p.95-115.

LIMA, J. S. et. al. Programa de biomonitoramento da qualidade do ar da cidade do Salvador proposta e resultados preliminares. In: CONGRESSO BRASILEIRO DE ENGENHARIA SANITÁRIA E AMBIENTAL, 23, 2005, Campo Grande. Anais do 23ํㅡㄴ Congresso Brasileiro de Engenharia Sanitária e ambiental. Campo Grande: ABES, 2005. Disponível em: http://www.laviet.ufb.br. Acesso em: 23/02/2007.

LIRIA, C. W. et. al. Manual de Metodologia do Trabalho Científico. Faculdades Oswaldo Cruz. São Paulo. 2006.

LUIZ, E. J. et. al. Sentindo a Cidade: Biomonitoramento da Qualidade do Ar de Santo André com plantas da espécie Tradescantia pallida e a Educação Ambiental. Secretaria Municipal de Saneamento Ambiental de Santo André. São Paulo, 2005.16p. Disponível em: www.semasa.sp.gov.br/admin/biblioteca. Acesso em: 16/03/2007.

MANCHETE. PORTAL DO GOVERNO DO RIO GRANDE DO SUL. Boletim n.244.Disponível em: www.estado.rs.gov.br/principal_manchete.php. Acesso em:20/03/2007.

MENDONÇA.B.R.;SILVA, E.A.; SILVA, E.A.M. Efeito da poluição sobre bioindicadores vegetais. Ambiente; Revista CETESB de Tecnologia. v.5, n.1, 1991, p. 37-40.

MORAES, R. M. ; DELITTI, W. B. C.; MORAES, J. A. P. V. Respostas de indivíduos jovens de Tibouchina pulchra Cogn, à poluição aérea de Cubatão, SP: fotossíntese líquida, crescimento e química foliar. Rev. Brasil. Bot., São Paulo, v. 23, n. 4, 2000, p. 443-449.

MOTA, S. Introdução à engenharia ambiental. 2. ed. aum. - Rio de Janeiro: ABES, 2000, p. 205-227.

O IBAMA e sua História. Disponível em: http://www.ibama.gov.br/institucionalhistoria/index.htm. Acesso em 02/04/2007.

OLIVA, M. A. e FIGUEIREDO, J. G. Gramíneas bioindicadoras da presença de flúor em regiões tropicais. Rev. Brasil. Bot., São Paulo, v. 28, n. 2, 2005, p. 389-397. 
OLIVEIRA, F. N. S.; FREIRE, F. das C. O.; AQUINO, A. R. L. Bioindicadores de Impacto Ambiental em Sistemas Agrícolas Orgânicos. Embrapa, Dez 2004, Documentos 93, CE.

PAULA, M.T. et al. Influência do flúor sobre parâmetros químicos e bioquímicos de folhas de muruci (Byrsonima crassifólia [ L.] Rich.). Rev. Ciênc. Agrár., Belém, n.43, 2005, p.137-148

PEDROSO, A. N. V. Avaliação estrutural de Nicotiana tabacum 'Bel W3' sob diferentes níveis de contaminação atmosférica. 2006. 60 p. Dissertação (mestrado) Instituto de Botânica da Secretaria de Estado do Meio Ambiente.

PINHEIRO, A. C. F. B.; PINHEIRO, A. L. F. B.; MONTEIRO, A. Ciências do Ambiente: ecologia, poluição e impacto ambiental. São Paulo: Makron, 1992. p.49-65.

Portal do Governo do Estado do Rio Grande do Sul. Boletim de n. 0244, 06/03/06 Manchetes. Disponível em: http://www.estado.rs.gov.br/principal_manchete.php. Acesso em: 28/03/2007. Portal da Secretaria da Saúde, Rio Grande do Sul, 07 maio 2006. http://www.saude.rs.gov.br/wsa/portal.

PRADO, J. F. Uso de bioindicadores para monitoramento do ar. Ambiente: Revista CETESB de Tecnologia; v. 07, n. 1, 1993, p. 58-64. Disponível em: http://bases.bireme.br/cgi-bin/wxislind.exe/iah/online/. Acesso em: 03/04/2007.

ROSEIRO, M.N.V.; TAKAYANAGUI, A.M. Morbidade por problemas respiratórios em Ribeirão Preto(SP) de 1995 a 2001, segundo indicadores ambientais, sociais e econômicos / Morbidity by respiratory problems in Ribeirão Preto (SP) from 1995 to 2001, according to environmental, social and economical indicators. Rev. Paulista de Pediatria. v. 24, n. 2, 2006. p. 163-170.

SAIKI, M. Estação verde. Rev. Pesquisa FAPESP. ed. 104, versão impressa.2004. Disponível em: http://www.revistapesquisa.fapesp.br/extras/imprimir.php. Acesso em: 13/03/2007.

SANT'ANNA, E.T.G. Poluição atmosférica urbana na cidade de São Paulo e mutagênese: avaliação de riscos utilizando-se bioindicadores vegetais do gênero Tradescantia/Urbana ir pollution in the city of São Paulo and mutagenesis: evaluation of risks using plant bioindicators of the genus Tradescantia. Tese (Doutorado em Fisiopatologia Experimental). Universidade de São Paulo. São Paulo.2003. 150p.

SILVA, C.J.; SASSON, S. Biologia. v. único, 3 ed.reform. Saraiva, São Paulo. p.364-377. SILVA, L. C.; AZEVEDO, A. L.; SILVA, E. A.M.; OLIVA, M.A. Flúor em chuva simulada: sintomatologia e efeitos sobre a estrutura foliar e o crescimento de plantas arbóreas. Rev. 
Brasil. Bot., São Paulo, v. 23, n.4, 2000. p. 385-393. Disponível em: http://www.jardineiro.net/botânica/banco/4trapoerabaroxa.php. Acesso em: 31/03/2007.

SILVA, V.G. Legislação Ambiental Comentada. 3. ed. Ver. e ampl., Belo Horizonte:Fórum, 2006. 560 . 